The impact of the Phonics Screening Check on grouping by ability: a 'necessary evil' amid the policy storm

\author{
Alice Bradbury \\ UCL Institute of Education, \\ University College London, \\ 20 Bedford Way \\ London WC1H 0AL \\ @ alicejbradbury
}

UCL Institute of Education, University College London, London, UK 


\title{
The impact of the Phonics Screening Check on grouping by ability: a 'necessary evil' amid the policy storm
}

\begin{abstract}
This article examines the impact of a statutory assessment in England, the Phonics Screening Check (PSC), on classroom practices of grouping children by 'ability'. Bearing in mind the argument that assessment is the rudder that steers the otherwise slow moving battleship of educational practice (Stobart 2008), it is argued that the PSC has altered how teachers organise their classes and curriculum in both the affected year group (Year 1, children aged 5-6) and in earlier and later years. Using data from a nationwide survey of teachers $(n=1373)$, focus groups, and in-depth interviews with teachers, the paper examines how this relatively new phonics assessment forms part of a 'policy storm' of pressures relating to accountability, which encourage teachers to place children in groups on the basis of ability, even when they have doubts about this practice and there is little evidence to suggest grouping improves attainment (Taylor et al. 2016). Practices include grouping children within classes, across year groups or even across several years groups, by phase of phonics learning, guided by advice from bought-in private phonics schemes. There is also evidence of 'educational triage' (Gillborn and Youdell, 2000) where borderline children become the focus, and increased use of interventions which involve withdrawing children. Overall the paper uses the PSC to demonstrate how in times of multiple policy pressures, assessment can rapidly alter practice, in this case making grouping a 'necessary evil', as one teacher respondent argued.
\end{abstract}

Keywords: Assessment, ability grouping, early years, phonics

\section{Introduction}

Assessment policy is sometimes described as the rudder that steers the battleship of education (Stobart 2008). In this analogy, the course of the slow-moving ship of established practice can only be altered by changes to assessments. Bearing in mind this analogy, this paper explores how a new assessment policy - the introduction of the statutory Phonics Screening Check in England - has altered how teachers organise their classes and curriculum in both the affected year group (Year 1, children aged 5-6) and in earlier and later years (Reception and Nursery, age 4-5 and 3-4 years, and Year 2, age 6-7). The research findings detailed here demonstrate that this analogy is accurate in terms of the impact on classroom practice of a new assessment. Using data from a nationwide survey of teachers $(n=1373)$, focus groups and in-depth interviews with teachers, I argue that this new assessment forms an important part of a policy storm of pressures, which encourage teachers to place children in groups on the basis of ability ${ }^{1}$. These practices occur despite the evidence that this is not an effective method of improving attainment (Taylor et al. 2016) and the concerns about the impact on children (Bradbury and Roberts-Holmes 2017a). Grouping becomes a 'necessary evil', to quote one respondent, further demonstrating the power of assessment to steer pedagogy.

The Phonics Screening Check (PSC) was introduced in 2012 by the Conservative-Liberal Democrat government, while Michael Gove was Secretary of State for Education. Originally described in the Conservative manifesto as a 'simple reading test', the policy evolved to become a test of phonic awareness (Bradbury $2014 \mathrm{~b}$ ). Children are required to decode 20 real words and 20 pseudo-words, which are phonetically plausible but have no meaning (e.g. vap, strom). This tests their knowledge 
of the 85 grapheme-phoneme correspondences, the sounds that can be made by letters or combinations of letters, in phonetically consistent words (for further discussion of the content of the PSC, see (Darnell, Solity, and Wall 2017). As Ellis and Moss note, the PSC 'is not a test of reading in its fullest sense, where meaning counts as well as decoding' $(2014,242)$; the words are presented without context.

The test has always been and remains controversial, due to the long-standing debates about the efficacy of synthetic phonics (see Wyse and Goswami 2008; Clark 2016), doubts about the role of the check in identifying children who struggle with phonics (Duff et al. 2015) and the inclusion of pseudo-words (Gibson and England 2016). The aim of the policy is to ostensibly to improve reading scores, by '[making] sure that all pupils have learned phonic decoding to an appropriate standard by the age of 6' (DfE 2012), although the increased role of synthetic phonics in teaching children to read continues to be the subject of fierce debate (Clark 2016; Davis 2012). For schools, the proportion of children passing the PSC in Year 1 (which means attaining a set score of around 32 out of a total of 40) has become a key part of the data on attainment assessed by Ofsted. If children do not pass, they are required to take the test again in Year 2. To facilitate preparation for the test and encourage the use of synthetic phonics, from 2011 the government provided matched funding of up to $£ 3000$ for schools to purchase phonics schemes from private companies on an approved list (DfE 2011). As discussed later, the most popular of these schemes is Read Write Inc, provided by Ruth Miskin training ${ }^{2}$. This is significant in this paper because the Read Write Inc scheme requires teachers to group pupils by phase of phonic knowledge, and thus the private company has an influence on pedagogy.

The PSC has to be seen in a wider policy context of the era of the early-mid 2010s, when, under Michael Gove's direction, the school system in England underwent significant reform (Ball 2017). There were changes to assessments at all ages, a new national curriculum was introduced in primary schools in 2013, and national curriculum levels were removed in 2015. Despite an agenda of 'slimmed down assessment', as stated by Gove, this period saw an increase in assessment with introduction of the PSC, and additional pressures related to accountability as the statutory assessments at age five and seven were made more demanding (Bradbury, 2014b). Bearing in mind this context of a policy storm, I examine here what research data on grouping practices reveals about the impact of the PSC, adding to the literature on this assessment and to wider research on the impact of assessment on pedagogy with new research dataI begin with a discussion of the research on grouping more widely, to provide context for the findings on grouping with young children.

\section{The critique of ability and its use in grouping children}

Before considering the research on grouping, it is important to note that the notion of ability is contested and complex, although it is widely used in education in England, often without question (Bradbury 2013; Gillborn and Youdell 2000). The idea of children as having a fixed, measurable ability is based on longstanding notions of hereditary intelligence, discernible through IQ tests (White 2006; Ball 2013) which continue to be debated in academic circles. The idea that some children are naturally 'bright' is a common-sense, every-day trope in schools and wider society, but the concomitant notion that some children are 'less able' or 'slow' is more controversial. Grouping practices are facilitated by this discourse of ability as inherited and permanent 
- what Marks refers to as 'fixed ability thinking' (2013). This discourse frequently determines the grouping practices of schools (Marks 2013), particularly in Maths, where the assumption of sequential learning means that it is 'the subject most tightly framed by tracking and performance measures' (Brown 2017). As I argue in later sections, this idea that some 'bright' children move more quickly through sequential stages of learning is important in Phonics too, as it provides the justification for grouping practices.

\section{Grouping practices}

This research was concerned with all forms of grouping children which make formal distinctions between pupils on a short or long-term basis. Within this term I include the following practices, as used widely:

- Streaming: When children are placed in a class, usually for the entire year, based on a general view of their ability across the curriculum.

- Setting: When children are placed in classes for particular subjects, mainly Literacy and Maths, and move from their normal class for this subject.

- (Within-class) Ability grouping: Where ability groups are used within a class, usually sat at different tables with different tasks and levels of support. This may occur in a mixed-ability class, or indeed within a set.

- Interventions: When specific children are targeted and removed from the class at regular times for additional support or extension activities; this is often for a fixed period of time and a specific purpose, such as booster groups used before assessments.

This final point is a departure from the commonly used list of grouping practices, however, I wish to bring the discussion of interventions into the debate on grouping practices, because interventions are a form of dividing children which is based on who is 'falling behind' or who is 'gifted and talented', which are notions based on ability. As with all educational practice, trends in grouping depend on the social and economic content of the time, the values dominating society, and the influence of psychological theories of intelligence (Ireson and Hallam 2001). The current use of interventions reflects the dominant discourse of progress for all evidenced by data (Bradbury and Roberts-Holmes 2017b); the idea that 'no one can fall behind', so that those not meeting the standard must be separated to resolve the problem. As Ireson and Hallam argue, decisions on grouping pupils are tied to ideological positions, based on particular visions of how education should function, and so they 'arouse strong feelings' (2001, 1); what I emphasise here is how strongly these practices are linked to the assessment regime in English primary schools.

\section{Research on grouping practices}

Following the long history of diverse forms of 'dividing practices' (Foucault 1982) in education in England, the era of a neoliberal marketised education system has seen a resurgence in the popularity of grouping in primary schools, motivated by increased pressure to meet attainment targets (Ireson and Hallam 2001, Marks 2016). In the 2000s both Labour and Coalition governments voiced their support for forms of grouping for younger children (Marks 2016), and the most up-to-date data from the Millennium Cohort Study suggests that $37 \%$ of children experience setting for Literacy or Maths in 
Year 2 (Hallam and Parsons 2013).

This resurgence runs counter to the wide body of research from the UK and elsewhere which has suggested that grouping by ability can have serious consequences for pupils, and the fact that 'it is well established that attainment-based grouping has little if any overall benefit in terms of student outcomes' (Taylor et al. 2016:2). While there may be some modest gains for higher-set students, there is a negative impact in lower attaining groups, both in academic and social terms (Campbell 2015).

Nonetheless, research with teachers and school leaders suggests they prefer to group children by ability (Hallam and Ireson 2007). This is based on a wider range of factors than only attempts to improve attainment, such as the idea that grouping allows students to learn at the right pace and level, making teaching easier, while mixed ability teaching 'places greater demands on the teacher' (Ireson and Hallam 2001:12).

Furthermore there is a strong perception among teachers that grouping allows the teacher to cater better for different children (Anthony, Hunter, and Hunter 2016); and 'enables pupils' curriculum needs to be better met' (Ireson and Hallam 2001, 151). Grouping is seen as being beneficial for higher attainers, as well as allowing the needs of lower attainers to be catered for, and perceived as a useful strategy to improve attainment overall (Hamilton and O'Hara 2011). Research suggests decisions on grouping are based on a 'concern to maximise adult-pupil interaction, teacher control and pupil on-task attention and efficiency' (Baines, Blatchford, and Kutnick 2003), not only for academic reasons. Indeed Dunne et al. (2011) found a significant mismatch between prior attainment and set placement in secondary schools, so that in their study less than half of pupils with low prior attainment were placed in low sets.

While teachers have concerns about the effects of more formal grouping practices such as setting, within-class grouping, which is more common in primary schools (but may be used in combination with setting) is seen as less damaging to children; groups within the class are 'often believed by teachers to be free of the iniquitous impacts of between-class ability grouping practices such as setting and streaming' in schools (Marks 2013, 35). However, Marks' research suggests that in primary classrooms where this occurs there are still damaging effects on children's selfesteem: in a Year 4 classroom, 'pupils took on, and saw themselves in terms of, group identifiers' (Marks 2013, 35; see also Marks 2016). Classrooms which are organised with different tables for groups result in greater child awareness (with the attendant impact on their self-esteem) than those where children are given different tasks but can choose where they sit (Hamilton and O'Hara 2011).

The wider research on grouping at all ages suggest that it affects 'pupils' selfesteem, academic self-concept and their emotional responses to school' (Ireson and Hallam 2001, 61). As Pykett comments, students 'quickly learn how the school, local authority or educational establishment perceive, pigeonhole and arguably limit their localised "aptitudes" or "aspirations"' (2012, 34 cited in Brown 2017, 403). Grouping potentially limits learning in formal and informal ways, by restricting access to more difficult content (Kutnick et al. 2005). This can widen gaps between low and high attainers as those in higher groups are stretched further while those deemed to be lower never access more complicated tasks (Parsons and Hallam 2014). Grouping 'entrenches variation between pupils', and damages attainment for those in lower groups, thus reproducing the 'spectrum' of attainment they are intended to reduce (Campbell 2013, 10; after Kutnick et al. 2005). International analysis of hundreds of studies suggests limited positive impact on learning, leading to grouping being described as 'being amongst the educational intervention "disasters"' (Mazzoli Smith and Campbell 2016, 258, in reference to Hattie 2008). 
The practice of interventions, where lower-attaining children are removed for additional work in literacy and maths, can result in a narrowed curriculum (Dunne et al. 2011), and some studies have found children in these groups are taught by lowerqualified teaching assistants in inappropriate teaching spaces (Brown 2017). Grouping practices are affected by the need to focus on particular borderline children in preparation for tests, in systems of 'educational triage' (Gillborn and Youdell 2000) including in early years classrooms (Roberts-Holmes 2015). While more experienced teachers may be allocated to the borderline children (Dunne et al. 2011), some children are deemed 'hopeless cases'.

Triage systems, like other forms of grouping, may exacerbate existing social inequalities by social background and ethnic group (Gillborn and Youdell, 2000). There is a range of research evidence that 'reinforces the view that ability grouping frequently leads to inequity and deepening disadvantage' (Hamilton and O'Hara 2011, 714); thus grouping children by ability is 'a social justice issue' (Jackson and Povey 2016, 1). Group allocation is not based solely on prior attainment; instead, a 'wide range of social factors come into play which privileges those with greater cultural power and systematically disadvantages others' (Jackson and Povey 2016, 2; see also Muijs and Dunne 2010). Social Mobility Commission (SMC) reports have highlighted the evidence that poorer pupils make less progress in schools when they are grouped by ability from an early age (SMC 2017), and warn that 'early setting (for example at primary school) is shown to reduce progress by pupils who begin primary school in lower ability groups. Setting can therefore have a profound negative impact on pupils' future social mobility at all key stages' (SMC 2016, 37). Disadvantaged children are more likely to be in lower sets and experience less well qualified staff (Francis et al. 2017; Dunne et al. 2011; Hallam and Ireson 2007; Kutnick, Blatchford, and Baines 2002). The over-allocation of Black and working-class students in lower sets in secondary schools has been described as a form of 'symbolic violence' (Archer et al. 2018).

Finally, for young children, allocation of sets is also affected by their month of birth (and thus their age on entry to school): data from the Millennium Cohort Study indicated that by Year 2, 'Children born in September are more than twice as likely to be in the highest stream as those born in August' (Campbell 2013, 3).

Although the literature on grouping is vast, there is little research on the specifics of grouping for Phonics, largely because this is a new phenomenon resulting from the introduction of the PCS in 2012. Here I address this gap by considering how grouping for Phonics fits into the wider picture of grouping at age 3-7 years.

\section{The research study}

This research study explored grouping practices in Key Stage 1 and early years (age 37) in primary schools, and teachers' views of these practices, using a mixed methods approach. The research questions that guided the project focused on the extent and nature of grouping practice, the first forms of grouping children experience, teachers' reasons for using grouping, and movement between groups. The project was funded by the National Education Union, the main teachers' trade union, but conducted independently without influence on methods. There were three components to the data collection. First, four focus groups were conducted with teachers which explored current practices of grouping, lasting 30-40minutes. Participants were selected through the NEU so all were union members working in primary schools ${ }^{3}$. These are labelled 
FG1-4. These focus group data were analysed and used to inform a national online survey of teachers (using Opinio software), which was circulated widely through social media channels. This was completed by 1373 people, who identified themselves as Nursery and Reception teachers $(31 \%)$, Year 1 or Year 2 teachers $(38 \%)$, early years or KS1 Phase leaders (14\%), support staff (4\%), senior leaders (4\%) and other (9\%). Respondents did not have to be affiliated to the NEU to respond. Written comments from the survey are labelled W. Finally, interviews were conducted with teachers in Key Stage 1 and early years and in other relevant senior roles at four case study schools: one in the Midlands (pseudonym Whiteread Primary), one in the north of England (Moore Primary), and two in London (Hepworth and Kapoor Primaries). These schools varied in terms of Ofsted rating and published attainment levels, size and local population. They were contacted independently by the research team and so did not have any connection to NEU. In total, 12 teachers and school leaders were interviewed using a semi-structured schedule focused on the details of practices and teachers' views. Their roles are described only by year group or as senior leader to increase anonymity.

In summary, the data used here are based on a range of teachers' and school leaders' views of grouping practices. Alternative viewpoints of the experiences of grouping practices could come from interviewing pupils and parents, but the aim of this project was to elicit the views of teachers and, to a lesser extent, school leaders.

The research adhered to the ethical guidelines of the British Education Research Association and approved by the [university] ethics research committee. All names used are pseudonyms and all attempts have been made to maximise anonymity of respondents.

The research data were analysed in relation to the research questions discussed above, using a theoretical framework guided by the key concept of disciplinary power (Foucault 1979), as operating through micropractices of power which constitute the 'pedagogical regime' (Gore 2001). Of particular relevance here are the three micropractices of classification, which is the use of truths to distinguish between children (for example, using the idea that ability is measurable to allocate children to groups); distribution, which is the use of truths to organise people physically in a space, such as in ability groups; and exclusion, which is the use of truths to create boundaries of normality and abnormality, such as in the case of children deemed 'behind' and in need of intervention (Gore 2001; MacNaughton 2005). This latter can operate in tandem with normalisation, as they are defined against each other. These concepts help in the interrogation of seemingly benign and common-sense classroom practices, which are, in small ways, operations of power upon human bodies and minds.

The research findings were presented via a press conference in November 2017 and the publication of a summary report, resulting in widespread media coverage (References removed for anonymity). Here, I return to the data to explore what we can learn about the relationship between assessment policy and classroom practice from primary schools in England, using the case of Phonics grouping practice.

\section{The Phonics phenomenon}

A striking finding from the initial focus groups with teachers was the extent to which Phonics was seen as a separate and distinct subject, rather than part of Reading (hence the capitalisation of Phonics). This lead to its inclusion on a list of subjects in the survey, where we asked about forms of grouping and frequency of movement, and specific questions in our interviews. Survey results showed that grouping was most 
common in Phonics (76\% responding that they 'group regularly'), followed by Maths $(62 \%)$, Reading (57\%) and Literacy (54\%). This varied by year group however, with $58 \%$ of Nursery teachers grouping for Phonics (age 3-4), 81\% of Reception teachers (age 4-5), 78\% in Year 1 (age 5-6) and 72\% in Year 2 (age 6-7). This echoes the finding of a DfE report in 2014, which noted that 'the majority of schools said they grouped children by ability for phonics sessions and that this was an increasing trend' (Walker et al 2014:8).

This distinction between Phonics and Reading is a relatively new phenomenon which is driven by the PSC in Year 1 (and the resits in Year 2). I note that my book on Reception classrooms, based on a year of ethnographic observation in 2008-9, makes no mention of Phonics as a separate subject. But recent research on the PSC has found that phonics is now a distinct area of the curriculum, informed by the demands of the test: for example, teachers include pseudo-words in their Phonics teaching (Walker et al. 2015). That Phonics is important and worthy of distinct curriculum time has become a new 'regime of truth' (Foucault, 1980) in early years and Key Stage 1; in turn alternative truths about reading for pleasure or even reading for meaning, lose their power (Clark, 2016).

In terms of grouping strategy, teachers reported a variety of practices of distribution: they grouped for Phonics within the class (31\%), across the year group (39\%), and unusually, across the age phase or the entire school (28\%). This final strategy is facilitated by the use of Phonics schemes such as Read Write Inc. from the Ruth Miskin company, which encourages grouping by phase of phonic knowledge (Ruth Miskin Training 2017, 6) - their influence is discussed in more detail below. These phases are part of the government's Letters and Sounds guidance document (DfES, 2007), but this document does not specify that children should be assessed as at a particular phase and grouping according to this. However in some case study schools, we found practices where children from Year 5 were sitting with Year 1 children to learn Phonics because they were deemed to be at that stage or phase of phonics learning:

The children in each [Phonics] group are from mixed years. So in Phase 2 we've got some Year 2s, some Year 3s, Year 1s. And in Phase 5 here we've got some Year 2s, some Year 4s, some very bright Year 1s. (School Leader, Kapoor Primary)

This unusual practice, not discussed in relation to other subjects, marks Phonics out as distinct, a special case requiring special practices. As one teacher commented on the survey:

Generally we don't use it [grouping] and we give children challenges to decide for themselves which level of challenge they want to attempt but in phonics we have to use Read Write inc with children working at different levels. (W).

The idea that learning is entirely sequential - as discussed in relation to mathematics (Marks 2016) - here appears to justify the need for grouping in all forms, and indeed make it appear neutral and necessary:

You have some children who already know all their sounds and everything like that, where you have other children who still can't hear a sound so it's very difficult to teach those children together. (School Leader, Moore Primary) 
I don't particularly like grouping phonics that much but because the children have got such different levels here... we had a cohort of children that started school after Christmas here and then after April as well and they didn't do any phonics in nursery so that means they're not even phase one. That means they're way behind. So we've been playing a big catch up game with them. (EYFS Coordinator, Whiteread Primary)

Here grouping appears practical and inevitable because children have had different exposure to phonics learning in nursery settings, so 'they have got such different levels'. But, whether phase-based groups are organised within class, the year group or the age range, I would argue that there is a danger that a child's allocation to a Phase comes to symbolise their ability, and that these are conflated. The phrase 'behind' in the quote above can very easily become 'below expectations', lower attaining, or low ability. These phases are forms of classification, demarcating children from their peers on the basis of progress in Phonics, and for some they represent an exclusion. Furthermore, the allocation of a child to a phonics Phase is likely to be earliest form of grouping they experience, as seen in the quote above when children are entering school. It was mentioned in relation to children as young as two in some cases:

In the nursery $[\ldots]$ we do have a little gifted and talented (I hate using that phrase), but I have a little group that I'm doing a bit more of a push with that are ready for it but only because they're absolutely ready. (FG3, in reference to two-year-olds)

Allocation to a Phonics group marks the first moment of division, where those deemed 'ahead' are split from those 'behind', and those who are 'gifted and talented' are marked out for a 'bit more of a push'. It labels children, or in Foucault's terms, classifies them, and in turn it excludes some children from positions of success.

A further form of the micropractice of exclusion occurred through interventions. In Kapoor Primary, there was a decision to move away from grouping for Phonics across the school to whole class groups, causing the school leader to make plans for intervention groups to compensate:

I'm going to pull out the children who have not made much progress in early years. So those that are coming up from early years with very little phase 2 segmenting and blending going on. [...] So I will pull out some Year 1s, some Year 2s, possibly some newly arrived children who are actually going to be in Year 4 but they're Romanian and they haven't been here for more than a few months and they're not picking up very quickly. So although they're Year 4, they're going to really benefit from the end of phase 2 with a big push. (School Leader, Kapoor Primary)

Here interventions are seen as a way to solve the problem of not grouping by 'pulling out' the children who are not making enough progress. Similarly at Whiteread Primary, a particular social group were targeted for additional reading support:

Yes, so the majority of the pupil premium are with me who are just one step behind where they should be. But then our pupil premium children don't do any reading at home, none. So then we have a TA, a teaching assistant, her job is just to read with the pupil premium children and to try to catch them up. (School Leader, Whiteread Primary) 
Here 'pupil premium children', whose entitlement to free school meals within the last six years (and the resulting funding for the school), defines them and labels them, are subject to a specific intervention to help them catch up with the reading that is seen as absent from home. They are 'one step behind' in a system which reifies progress (Bradbury and Roberts-Holmes 2016); a state which is removed from 'normality'. This concern with progress relates to the findings on the reasons for grouping for Phonics, which were largely based on the need to prepare for the PSC.

\section{The demands of the Phonics Screening Check}

Although the Phonics Screening Check is described as a 'light-touch' assessment (DfE, 2014), it functions as a high stakes assessment, used by Ofsted to judge the quality of Phonics teaching. Although it is controversial, nonetheless, it matters to schools, and the teachers in our research were clear that it had become a priority in key stage 1 and early years classrooms:

They do phonics early on. I think that the Year 1 phonics test has had that real impact of doing phonics groups. (FG2)

In Year 1 they are streamed by ability for phonics because of the phonics test. We've got a two-form entry school so they're mixed between the two classes by ability and they move to a different class, if necessary, for that. Again, then in the classes they are sat on tables [by ability]. (FG4)

Schools are under tremendous pressure and it's all about scores on the doors and data and targets and so on and so forth, despite knowing that this isn't what's best for our children, they are precious. The example I can give is in terms of streaming if you want, setting the children, it's phonics, in the first instance. (FG3, my emphasis)

Here we see how grouping is seen as a solution to the problem of the PSC. The assessment drives the pedagogy, even where teachers know 'this isn't what's best for our children'. This is performativity, and datafication, where the values and priorities of a setting are determined by the need to produce the performance as exemplified by data (Ball 2017; Bradbury and Roberts-Holmes 2017b). The test produces anxiety, which determines grouping strategies:

I think the only pressure we feel obviously is the phonics screening. Because we are- well, we're not unique but we're in a tricky situation. We're not dealing with white British families, we're dealing with a whole multi-faith, multi-cultural spectrum, and obviously there's more pressure on us to get a certain percentage to the pass rate. So we know that we are going to have to pull out all the stops to do it, so what is the best way of doing it? (School Leader, Kapoor Primary)

This school is described through a 'difficult intake' discourse which emphasises its exceptionality (Bradbury 2011), and thus the pressure means extra effort has to be made, and an effective grouping strategy is required. For many the strategy is motivated by the need to avoid failing, to avert the disaster of not getting the right percentage to pass, and thus grouping becomes a strategy of risk management: 
I think that's something behind the phonics bit is that because it's drilling for a test, grouping them might be the best way; but doing it for a whole class is a risk that people aren't willing to [take]. (FG2)

Here whole class teaching goes against the norm and involves risk, because it is not suited to the form of 'drilling' required by the test. There is no pretence here that the strategy is designed to help children learn to read; teachers are clear that their choices are shaped by the demands of the assessment. This is not to say, however, that they do not question the practice. Teachers we spoke to and those who answered the survey felt compromised by the need to group even when they feared the social and emotional consequences. I return to this notion on the 'necessary evil' in the discussion section below. I now consider in more detail a specific form of grouping in preparation for tests.

\section{Educational triage for the Phonics Screening Check}

'Educational triage', a term coined by Gillborn and Youdell (2000), refer to systems which ration resources, informed by the need to focus on children on the borderline who have the most impact on test results. Originally found in relation to secondary students at GCSE level (age 15/16), it involves dividing students into 'safe', 'borderline' and 'hopeless' cases, though these terms differ in different contexts ${ }^{4}$. It has been identified in school systems with high stakes tests around the world, with a range of different age groups (Booher-Jennings 2005; Youdell 2004) Ball et al 2012), including in early years in England (Roberts-Holmes 2015). It can be seen as a rational response to the pressures of performativity, but nonetheless it is simultaneously a form of distribution, classification and exclusion, delimiting who is useful in terms of results, and who is a 'hopeless case' (Youdell, 2004). In this research, teachers described - without prompting - three-way systems of triage in preparation for the PSC and a focus on borderline pupils, close to passing:

And sometimes we have children that are very much on the borderline and we know that there's a chance that they could achieve it, but we might not know until very near to the end of the year I think if they are going to or not. So they're the ones we will really look to get there. (Reception Teacher, Moore Primary, my emphasis)

In Year 1 they had a panic where these children don't know these things and so then they went to a panic measure of bringing it [grouping] in. So almost everybody was in with the teacher although it was differentiated, and then I took what was deemed, the "must get these children to pass their phonics check" group. [...] So they were obviously the children that they just went, "Well these ones aren't going to make it," so they're in the class doing something differentiated. Then there was the bulk going, "Yes, I think these ones are going to be fine." Then there were the other ones that they were like, "These have got to do it otherwise our score is going to be awful," basically. (FG3)

If you think about just in Year 1, you think, "Well these are the children that have to make it, they get the extra," [...] Do those ones who are at the bottom, do they get left and forgotten? (FG3)

While triage-type systems may be an inevitable consequence of a system where some pupils are 'worth' more to the school - what Ball et al describe as a method of 
'extract[ing] "productivity gains"' $(2012,72)$ - this final quote raises the ethical problem of dividing children in this way, however temporarily. A focus on one group means leaving others out, and previous research has suggested that this is a process which reinforces disparities in attainment by social class and ethnic group (Gillborn and Youdell, 2000). This clearly requires further research in relation to younger children, but there were some suggestions and concerns raised about the role of grouping in furthering social and racial disparities:

If they're not in the right group and they're not accessing the right learning, then they're not reaching their potential. So there are issues to do with race equality if you're not allowing children to access the curriculum that is right for them and reach their potential. (FG2)

Given the wider range of research on the reproduction of social inequalities through grouping (Gillborn and Youdell 2000; Archer et al. 2018), I would argue that systems of triage for the PSC may also reinforce disparities, by 'leaving behind' some children during this particular period. This may well operate alongside the systems of interventions already discussed, which involve withdrawing groups of children who are labelled 'pupil premium' or have English as an additional language. Indeed, this switch of prioritisation further suggests the idea that decisions are driven by pressure from the PSC rather than by a consistent approach to grouping. In both forms, there were suggestions in our data that there are inequities in terms of teaching staff, spaces and resources, reflecting the wider literature (Brown 2017; Taylor et al, 2017):

\footnotetext{
Phonics teaching hasn't been great in the past and what was happening was it was always the lowest ability children were out of class with a teaching assistant getting... and that was the phonics diet they had. So, you've got some children that were literally on Phase 2 forever. (School Leader, Moore Primary)
}

This quote belies of ideal of children moving from phase to phase, progressing when ready to the next stage of phonics knowledge. Even allowing for rhetorical exaggeration, the idea that some children remain on one phase 'forever' raises serious concerns about the emotional as well as social impact of phase-based grouping in Phonics.

\section{The role of Read Write Inc}

Finally, I return briefly to the issue of the influence of Read Write Inc, the phonics scheme provided by Ruth Miskin training (2017) and used by over 5000 schools (OxfordOwl 2017). This scheme, which is approved by the DfE, is used to justify and legitimise grouping practices even when teachers disagree, removing the decision from their professional judgement.

As mentioned above the Read Write Inc. programme recommends that children are organised by phonics phase across the year group or across several years. One teacher explained:

As soon as our children go into Key Stage 1, then we have a lot of streaming and a lot of setting. We do Read Write Inc as well. So the phonics is set and then we do the full literacy hour of Read Write Inc in Year 1 and Year 2. So across the whole of Key Stage 1 they're streamed and set into I think about 10 groups. (FG3) 
In this case, the scheme is used in Key Stage 1 and dictates grouping practice, but several other teachers explained Read Write Inc was used in Reception in preparation for the Phonics test. The link with the PSC was explicitly made in many cases, such as one survey respondent who commented: 'With Read Write Inc we have consistently had $96 \%+$ phonics test pass rate in our very mixed ability intakes' (W). Indeed, the scheme is explicitly marketed at schools that are concerned about their Phonics results, with a section of the website titled Are you set up for success in the Year 1 screening check? (Ruth Miskin Training, 2017).

One result of using this scheme is that teachers allocate groups based on a 'screening' system:

Because we screen all the time, so at the end of each term each teacher who has a phase group will test their group, every single one in their group. And they will literally, you know, go through, we'll test them and see if they know all the sounds. [...] And if we feel they've done exceedingly well they can go up. If they haven't done terribly well they'll stay put. (School Leader, Kapoor Primary)

Our phonics streaming with the Read Write Inc programme, it's not very fluid. They don't move very often because if they move quite often, I mean it's a big undertaking to the very structured assessments but also, where it's a very structured programme, if they move often, you'll find that they'll miss out and there'll be gaps. So generally, when they're in a set they stay in it for quite a while unless they've made real accelerated progress and can move but often they don't move very much. (FG4)

This system of moving up (or staying put) was based on half-termly tests of phonic knowledge, provided by Read Write Inc and phrased in pseudo-medical, diagnostic terms as a 'screening' process (much like the PSC itself). The scheme could enable movement based on these assessments, or result in quite fixed sets as in the second quote above. We see how in some schools, Read Write Inc has great influence over how the teaching of phonics and reading more widely is understood; it becomes a frame through which pedagogy in these areas is discussed. As one teacher commented, 'The way in which 'ability' is defined in my school is through the Read Write Inc assessment scheme' (W), suggesting the conflation of success in phonics tests with wider ability. Even where these is disagreement with grouping, the scheme limits how this can be challenged: one teacher argued 'Ability grouping shouldn't be done. Read write Inc phonics doesn't work if you don't though' (W).

This influence is part of a wider project of greater private influence in education (Ball, Junemann, and Santori 2017), and symptomatic of a system where decisions to adopt such schemes are guided by the pressure of high stakes tests. Again, this requires further discussion and research, but it is clear that Read Write Inc is important in decisions about how to organise teaching Phonics and thus is a key part of the policy enactment process.

\section{Discussion}

The data presented here suggest that the Phonics Screening Check has had a strong influence on pedagogical decisions in relation to grouping. Teachers in Key Stage 1 and early years group their pupils because of the pressure of a high stakes test, but they do have serious doubts about this process and are aware of the potential emotional and 
social consequences (as discussed in more detail in (Bradbury and Roberts-Holmes, 2017a). Grouping is, to quote one teacher, a 'necessary evil'; for another, 'in a climate of results I also think it is a necessary means to an end in many circumstances' (W). Thus teachers are positioned as unwilling agents in a complex policy context, in a similar fashion to this description of the reaction of teachers to a different new assessment system (Baseline Assessment):

... their professional identities are bound up with this process of constantly adapting to change; they simply 'sigh' and carry on, or see it 'as just one of those things'. They are ships buffeted by the latest storm; flexible, adaptable, willing, just as the neoliberal education system requires them to be (Bradbury and RobertsHolmes 2017b, 59-60)

These teachers' willingness to use grouping despite their concerns reveals this flexibility, and responsiveness to policy imperatives. As found in secondary education, despite 'murmurings' of 'different rationalities' the intense nature of working in a school means teachers are required to move between different subjectivities as 'incoherent subjects' (Ball et al, 2012, 95).

To return to the wider battleship analogy, we can see how assessment works powerfully as the rudder of the ship of education, turning the focus and practices to those deemed most 'effective' for high stakes tests. This is not a slow gradual shift, but a relatively quick response; the PSC had only been in place for five years when this research was conducted. In 2014, I argued in a discussion of the potential impact of the PSC that: 'the Coalition government has managed to change what teachers teach, and in turn what is valued within Year 1 classrooms' (Bradbury 2014a). What I did not anticipate, however, was the extent to which the focus on Phonics would reach down into early years, or the speed of this shift.

This rapid impact has to be seen in the context of a 'policy storm' in the early 2010s, where a series of policies from the Conservative and Liberal Democrat government were simultaneously enacted in schools in a process of "whole system reform' (Morris 2012) see also Wright, 2012). These included the removal of National Curriculum levels, which were a well-established system of assessing pupils in primary schools, a revised national curriculum, the introduction of performance related pay, greater responsibility for schools in training teachers, and revisions to statutory assessments at age five, seven and 11. Coming in the midst of these significant changes, the introduction of the PSC brought additional pressures to schools already under strain. In the midst of 'policy fatigue', as we might characterise it, it is not surprising that teachers begin to rely on guidance from private companies or fall back on practices like grouping by ability, where differentiation can be easily demonstrated. It remains to be seen if a similar single-skill test, the Multiplications Tables Test in Year 4 (age 8/9), due to be trialled in 2018 (DfE, 2018), will have similarly significant impact on pedagogy, coming as it does during a calmer time for schools.

\section{Conclusion}

This paper has discussed the impact of the Phonics Screening Check, a statutory assessment of phonic awareness at age 5-6, on grouping practices in classrooms for children aged 3-7 years. I have argued that the PSC has engendered practices of grouping by ability with children from Nursery classes onwards, and that this is seen as 
necessary. Grouping practices vary, but include grouping children by 'phase' across the year group or key stage, so that children from different year groups are placed together, and also systems of 'triage' which prioritise those children on the borderline. These can be conceptualised, following Foucault (1979), as micropractices of power, where 'truths' about learning and ability serve to classify, distribute and exclude children (Gore 2001). Private companies such as Ruth Miskin Training provide schemes for Phonics which encourage particular grouping practices, and have great influence on how children are organised.

These findings reflect a wider international literature on the impact of high stakes tests, which has found evidence of a narrowed or altered curriculum, 'teaching to the test', prioritisation of borderline children, and conflicted feelings about pressure and practice from teachers (Stobart 2008; Au 2011; Lingard and Sellar 2013; Thompson and Cook 2014). The case of the PSC and grouping practice provides another example of what can happen when "the assessment tail starts to wag the education dog", to quote O'Neill (2013). Moreover, this case demonstrates the power of high stakes testing in forcing teachers to act against their views on what is best for the children in their classes, and how rapid changes to practice can be when a new test arrives amid a number of other policy changes; grouping is a 'necessary evil' amid the policy storm.

\section{References}

Anthony, G., R. Hunter, and J. Hunter. 2016. "Whither Ability Grouping: Changing the Object of Groupwork." Mathematics Education Research Group of Australasia. Archer, L., Francis, B., Miller, S., Taylor, B., Tereshchenko, A., Mazenod, A., Pepper, D. and Travers, M.-C. (2018), The symbolic violence of setting: A Bourdieusian analysis of mixed methods data on secondary students' views about setting. British Education Research Journal, 44: 119-140. doi:10.1002/berj.3321

Archer, L., B. Francis, S. Miller, B. Taylor, A. Tereschenko, A. Mazenod, D. Pepper, and M. Travers. 2018. "The symbolic violence of setting: A Bourdieusian analysis of mixed methods data on secondary students' views about setting." British Educational Research Journal.

$\mathrm{Au}$, W. 2011. "Teaching under the new Taylorism: high-stakes testing and the standardization of the 21st century curriculum." Journal of Curriculum Studies 43 (1):25-45. doi: 10.1080/00220272.2010.521261.

Baines, E., P. Blatchford, and P. Kutnick. 2003. "Changes in grouping practices over primary and secondary school." International Journal of Educational Research 39 (1):9-34.

Ball, S. 2017. The education debate (third edition). Bristol: Policy Press.

Ball, S., C. Junemann, and D. Santori. 2017. Edu.net: Globalisation and Education Policy Mobility London: Routledge.

Ball, S. 2013. Foucault, Power and Education. Abingdon: Routledge.

Booher-Jennings, J. 2005. "Below the Bubble: 'Educational Triage' and the Texas Accountability System." American Educational Research Journal 42 (2):23168.

Bradbury, A. 2013. Understanding Early Years Inequality: policy, assessment and young children's identities. London: Routledge. 
Bradbury, A. (2014a) Phonics test: changing pedagogy through assessment, IOE Blog, Accessed 11 May 2018 at https://ioelondonblog.wordpress.com/2014/09/30/phonics-test-changingpedagogy-through-assessment/

Bradbury, A. (2014b). 'Slimmed down' assessment or increased accountability? Teachers, elections and UK government assessment policy. Oxford Review of Education, 40(5), 610-627.

Bradbury, A., \& Roberts-Holmes, G. (2016). Creating an Ofsted story: the role of early years assessment data in schools' narratives of progress. British Journal of Sociology of Education, 38(7), 943-955.

Bradbury, A., \& Roberts-Holmes, G. (2017a). Grouping in Early Years and Key Stage 1: a 'necessary evil'? London: National Education Union.

Bradbury, A., \& Roberts-Holmes, G. (2017b). The Datafication of Early Years and Primary Education: Playing with numbers.

Brown, C. 2017. "'Favourite places in school' for lower-set 'ability' pupils: school groupings practices and children's spatial orientations." Children's Geographies 15 (4):399-412. doi: 10.1080/14733285.2016.1269154.

Campbell, T. 2013. "In-school ability grouping and the month of birth effect." Preliminary evidence from the Millenium Cohort Study. London: Centre for Longitudinal Studies.

Campbell, T. 2015. "Stereotyped at Seven? Biases in Teacher Judgement of Pupils' Ability and Attainment." Journal of Social Policy 44 (03):517-47. doi: doi:10.1017/S0047279415000227.

Clark, M. (2014) The phonics check three years on: An analysis of the evidence and its implications, Education Journal, 210, 14-16

Clark, M. 2016. "Learning to be literate: Insights from research for policy and practice." Improving Schools 19 (2):129-40.

Darnell, C., J Solity, and H. Wall. 2017. "Decoding the phonics screening check." British Educational Research Journal 43 (3):505-27.

Davies, A. 2012. "A Monstrous Regimen of Synthetic Phonics: Fantasies of Research-Based Teaching 'Methods' Versus Real Teaching." Journal of Philosophy of Education 46 (4):560-73.

Davis, A. A Critique of Pure Teaching Methods and the Case of Synthetic Phonics.

DfE (2011) The importance of phonics: A catalogue of systematic synthetic phonics products and training (London, HMSO)

DfE, (2018) Multiplication Tables Check Trials to being in Schools Available at: https://www.gov.uk/government/news/multiplication-tables-check-trials-tobegin-in-schools [Accessed 2 March 2018]

DfE. "Year 1 phonics screening check FAQs." Accessed 28 January 2013. http://www.education.gov.uk/schools/teachingandlearning/pedagogy/a00198207 /faqs-year-1-phonics-screening-check.

DfES (2007) Letters and Sounds: Principles and Practice of High Quality Phonics London, Department for Education and Skills, Accessed 24 October 2017 from: https://www.gov.uk/government/uploads/system/uploads/attachment_data/file/1 90599/Letters_and_Sounds_-_DFES-00281-2007.pdf

Duff, F., S. Mengoni, A. Bailey, and M. Snowling. 2015. "Validity and sensitivity of the phonics screening check: implications for practice." Journal of Research in Reading 38 (2):109-23. 
Dunne, M., S. Humphreys, A. Dyson, J. Sebba, F. Gallannaugh, and D. Muijs. 2011. "The teaching and learning of pupils in low-attainment sets." The Curriculum Journal 22 (4):485-513. doi: 10.1080/09585176.2011.627206.

Ellis, S. and G. Moss. 2014. "Ethics, education policy and research: The phonics question reconsidered." British Educational Research Journal 40 (2):241-60.

Foucault, M. (1980). Power-knowledge: selected interviews and other writings, 19721977. Brighton: Harvester Press.

Foucault, M. 1982. "The subject and power." Critical inquiry 8 (4):777-95.

Francis, B., L. Archer, J. Hodgen, D. Pepper, B. Taylor, and M. Travers. 2017. "Exploring the relative lack of impact of research on 'ability grouping' in England: a discourse analytic account." Cambridge Journal of Education 47 (1):1-17. doi: 10.1080/0305764X.2015.1093095.

Gibson, H., and J. England. 2016. "The inclusion of pseudowords within the year one phonics 'Screening Check'in English primary schools." Cambridge Journal of Education 46 (4):491-507.

Gillborn, D., and D. Youdell. 2000. Rationing education: policy, practice, reform and equity. Buckingham: Open University Press.

Gore, J. 2001. "Disciplining bodies: On the continuity of power relations in pedagogy." Learning, space and identity:167-81.

Hallam, S. and J. Ireson. 2007. "Secondary school pupils' satisfaction with their ability grouping placements." British Educational Research Journal 33 (1):27-45.

Hamilton, L., and P. O'Hara. 2011. "The tyranny of setting (ability grouping): Challenges to inclusion in Scottish primary schools." Teaching and Teacher Education 27 (4):712-21.

Hattie, J. 2008. Visible learning: A synthesis of over 800 meta-analyses relating to achievement: Routledge.

Ireson, J., and S. Hallam. 2001. Ability grouping in education: Sage.

Jackson, C., and H. Povey. 2016. ""No, it just didn't work": a teacher's reflections on all attainment teaching." In CREME 10: 10th Congress for European Research in Mathematics Education. Dublin.

Kutnick, P., J. Sebba, P. Blatchford, M. Galton, J. Thorp, H. MacIntyre, and L. Berdondini. "The effects of pupil grouping: Literature review." Accessed 29 August 2017. http://dera.ioe.ac.uk/18143/1/RR688.pdf.

Kutnick, P., P. Blatchford, and E. Baines. 2002. "Pupil groupings in primary school classrooms: sites for learning and social pedagogy?" British Educational Research Journal 28 (2):187-206.

Levin, B. 1998. "An epidemic of education policy:(what) can we learn from each other?" Comparative education 34 (2):131-41.

Lingard, B., and S. Sellar. 2013. "'Catalyst data': perverse systemic effects of audit and accountability in Australian schooling." Journal of Education Policy 28 (5):634-56. doi: 10.1080/02680939.2012.758815.

MacNaughton, G. 2005. Doing Foucault in early childhood studies: applying poststructural ideas, Contesting early childhood series. London: Routledge.

Marks, R. 2013. "" The blue table means you don't have a clue": the persistence of fixed-ability thinking and practices in primary mathematics in English schools." Forum: For Promoting 3-19 Comprehensive Education 55 (1):31-44.

Marks, R. 2016. Ability-grouping in primary schools: Case studies and critical debates: Critical Publishing. 
Mazzoli Smith, L., and R. Campbell. 2016. "So-called giftedness and teacher education: issues of equity and inclusion." Teachers and Teaching 22 (2):255-67. doi: 10.1080/13540602.2015.1055448.

Morris, P. 2012. "Pick 'n' mix, select and project; policy borrowing and the quest for 'world class' schooling: an analysis of the 2010 schools White Paper." Journal of Education Policy 27 (1):89-107. doi: 10.1080/02680939.2011.596226.

Muijs, D., and M. Dunne. 2010. "Setting by ability - or is it? A quantitative study of determinants of set placement in English secondary schools." Educational Research 52 (4):391-407. doi: 10.1080/00131881.2010.524750.

O’Neill, O. (2013) Intelligent accountability in education, Oxford Review of Education, 39:1, 4-16, DOI: 10.1080/03054985.2013.764761

OxfordOwl (2017) Read Write Inc Phonics, Retrieved 18 October 2017, from: https://www.oxfordowl.co.uk/for-home/find-a-book/read-write-inc-phonics--1/

Parsons, S., and S. Hallam. 2014. "The impact of streaming on attainment at age seven: evidence from the Millennium Cohort Study." Oxford Review of Education 40 (5):567-89.

Roberts-Holmes, G. 2015. "The 'datafication' of early years pedagogy: 'if the teaching is good, the data should be good and if there's bad teaching, there is bad data'." Journal of Education Policy 30 (3):302-15. doi: 10.1080/02680939.2014.924561.

Ruth Miskin Training (2017) School policy on the teaching of phonics, reading and writing Retrieved 1st September 2017, from

http://www.ruthmiskin.com/media/resource_files/policy_on_phonics_reading_a nd_writing_7xq7xPG.pdf

Social Mobility Commission (2016) Ethnicity, Gender and Social Mobility Accessed 1st September 2017, from http://www.gov.uk/government/uploads/system/uploads/attachment_data/file/57 9988/Ethnicity_gender_and_social_mobility.pdf

Social Mobility Commission (2017) Low income pupils' progress at secondary school. Accessed1st September 2017, from https://cdn.lkmco.org/wpcontent/uploads/2017/02/SMC-Progress-at-Secondary-School-Shaw-et-al.LKMco-Datalab.pdf

Stobart, G. 2008. Testing times: the uses and abuses of assessment. London: Routledge. Taylor, B., B. Francis, L. Archer, J. Hodgen, D. Pepper, A. Tereshchenko, and M. Travers. 2016. "Factors deterring schools from mixed attainment teaching practice." Pedagogy, Culture \& Society:1-16. doi: 10.1080/14681366.2016.1256908.

Thompson, G., and I. Cook. 2014. "Manipulating the data: teaching and NAPLAN in the control society." Discourse: Studies in the Cultural Politics of Education 35 (1):129-42. doi: 10.1080/01596306.2012.739472.

Walker, M., M. Sainsbury, J. Worth, H. Bamforth, and H. Betts. 2015. "Phonics screening check evaluation."

White, J.. 2006. Intelligence, Destiny and Education: the ideological roots of intelligence testing. London: Routledge.

Wright, A. (2012) Fantasies of Empowerment: Mapping Neoliberal Discourse in the Coalition Government's Schools Policy, Journal of Education Policy 27(3), 279294

Wyse, D., and U. Goswami. 2008. "Synthetic phonics and the teaching of reading."

British Educational Research Journal 34 (6):691-710. doi:

10.1080/01411920802268912. 
Youdell, D. 2004. "Engineering school markets, constituting schools and subjectivating students: the bureaucratic, institutional and classroom dimensions of educational triage." Journal of Education Policy 19 (4):407 - 31.

1 'Ability' is a contested term, as I discuss later in the paper, but for ease of reading I refrain from putting it in quote marks from this point onwards.

${ }^{2}$ Ruth Miskin was one of the four 'phonics experts' who designed the PSC (Darnell, Solity, and Wall 2017).

${ }^{3}$ The National Education Union is the largest teachers' union in the UK with over 450,000 teachers as members. Thus although these participants were contacted through the NEU they do not represent a minority group in terms of the teacher population.

${ }^{4}$ Examples of other terms include 'bubble kids' in the US and 'cusp children' in the UK. 